\title{
Macrophage involvement in Epstein-Barr virus-related tumors
}

\author{
MISUZU SHIMAKAGE ${ }^{1}$ and HARUHIKO SAKAMOTO ${ }^{2}$ \\ ${ }^{1}$ Department of Pediatrics, National Hospital Organization, Wakayama National Hospital, Wakayama 644-0044; \\ ${ }^{2}$ Department of Pathology, Faculty of Medicine, Kagawa University, Kagawa 761-0793, Japan
}

Received November 30, 2009; Accepted January 15, 2010

DOI: 10.3892/etm_00000044

\begin{abstract}
Epstein-Barr virus (EBV) is known as a causative agent of Burkitt's lymphoma, nasopharyngeal carcinoma and approximately $10 \%$ of stomach carcinoma cases. In other human cancers, EBV gene expression including lytic infection protein detected using in situ hybridization and immunofluorescence staining has been reported. Moreover, the expression and replication of EBV genes in cultured normal macrophages and in histiocytes of Langerhans' cell histiocytosis have been identified. The aim of this study was to examine EBV expression in macrophages in other EBV-associated human tumors. Forty-one cases of EBV-associated tumors, which had been confirmed to express EBV, were examined. Tissue sections after in situ hybridization were double-stained immunohistochemically with the monoclonal anti-CD68 antibody. EBV expression in macrophages in the lesions of nasopharyngeal carcinoma, oral cancer, thyroid carcinoma, renal cell carcinoma, testicular carcinoma, uterine carcinoma, cutaneous T-cell lymphoma and anaplastic large-cell lymphoma was identified, whereas macrophages in normal or non-cancerous lesions showed no EBV expression. Many tumor-associated macrophages in EBV-related tumors carry EBV, which appears to induce the EBV lytic infection of macrophages. Therefore, the possibility that the lytic infection of macrophages by EBV and the resulting inflammation play certain roles in the oncogenesis of EBV-associated human tumors was raised.
\end{abstract}

Correspondence to: Dr Misuzu Shimakage, Department of Pediatrics, National Hospital Organization, Wakayama National Hospital, 1138 Wada, Mihama-cho, Hidaka-gun, Wakayama 644-0044, Japan

E-mail: misuzu_s@wakayama2.hosp.go.jp

Abbreviations: EBV, Epstein-Barr virus; LCH, Langerhans' cell histiocytosis; TAM, tumor-associated macrophages; NPC, nasopharyngeal carcinoma; RCC, renal cell carcinoma; CTCL, cutaneous T-cell lymphoma; ALCL, anaplastic large-cell lymphoma; EBER1, EBV-encoded non-polyadenylated RNA-1; EBNA2, EBV nuclear antigen-2; EBNA LP, EBV nuclear antigen leader protein; BZLF1, BamHIZ coding leftward reading frame-1; CIN, cervical intraepithelial neoplasia

Key words: macrophage, Epstein-Barr virus, inflammation, in situ hybridization

\section{Introduction}

It has been proposed that inflammation causes cancer $(1,2)$, and that approximately $18 \%$ of the global cancer burden is attributable to infectious agents (3). Epstein-Barr virus (EBV) is a ubiquitous DNA tumor virus, infecting almost all adults worldwide. On the other hand, EBV has been thought to cause some restricted tumors such as nasopharyngeal carcinoma, which occurs frequently in Chinese populations, Burkitt's lymphoma, which occurs in children in East Africa, or approximately $10 \%$ of gastric carcinoma cases. It is difficult to explain why the widely distributed EBV causes endemic tumors in such restricted areas or races. We hypothesized that EBV causes a wider variety of human tumors more frequently than is thought at present. In studies using the mRNA in situ hybridization method, it has been reported that EBV genes are expressed in oral carcinoma (4), mesopharyngeal and hypopharyngeal carcinoma (5), thyroid carcinoma (6), renal cell carcinoma (7), testicular tumors (8), uterine cervical carcinoma (9-11), anaplastic large-cell lymphoma $(12,13)$, cutaneous T-cell lymphoma (14), primary leptomeningeal lymphoma (15) and lymphoma originating in the lung (16). Most of these tumors expressed several EBV mRNAs and proteins. Other human tumors may also be associated with EBV infection. This needs to be extensively examined using several EBV mRNA probes, antibodies and primers. We frequently used EBV-encoded non-polyadenylated RNA-1 (EBER1) in situ hybridization in this study due to EBER expression in the nucleus and macrophage CD68 expression in the cytoplasm, and so the double staining was clearly visible. Other EBV mRNAs, for example EBV nuclear antigen-2 (EBNA2), which is an oncogene of EBV, are also important. In this study, we used four EBV probes: BamHIW, EBNA2, EBV nuclear antigen leader protein (EBNA LP) and EBER1. We detected EBNA2 mRNA and protein in almost all of the tumors $(4,6,7,10,14-16)$. In the tumor cells mentioned above, the frequency of a correlation with EBV was very high (more than 90\%) in each disease. Through these studies, the expression of EBV lytic infection protein BZLF1 by means of indirect immunofluorescence staining in the tumor cells as well as infiltrating lymphocytes was frequently observed. It is generally believed that EBV-related tumor cells express limited genes which operate in tumorigenesis, but do not express lytic proteins. However, Hoshikawa et al reported evidence of lytic EBV infection in EBV-positive gastric carcinoma (17). Furthermore, Takasaka et al observed EBV 
particles in established human gastric cancer cell lines by employing electron microscopy (18). These reports suggest the presence of productive EBV infection in human gastric cancer cells. Therefore, not only EBV-carrying lymphocytes, but also tumor cells may produce EBV. Lytic EBV infection of multiple tissues, may provoke a strong inflammatory response, since cell lysis induced by virus replication results in marked immune responses against viral proteins.

Macrophages are derived from bone marrow promonocytes, which develop into monocytes and infiltrate tissues. There, they differentiate into a specific type of resident tissue macrophage, such as microglial cells in the brain, Kupffer cells in the liver and Langerhans' cells in the skin. Their functions are to protect the host from microbial infection, to regulate tissue remodeling and to repair injury. Macrophages also comprise a major component of the inflammatory infiltrate in tumors. Such cells are termed tumor-associated macrophages (TAMs). TAMs can kill tumor cells, but they also produce growth factors, angiogenic factors and proteases which degrade the matrix. Through the action of these macrophagederived factors, tumor cell proliferation, angiogenesis, tumor invasion and metastasis are accelerated (19).

EBV infection of a macrophage cell line was first described by Revoltella et al (20). Furthermore, Savard et al reported a lytic program of primary human macrophages induced by EBV (21). We also showed the expression and replication of EBV genes in cultured normal human macrophages (22) and abnormal histiocytes in Langerhans' cell histiocytosis (LCH) $(23,24)$. Moreover, we revealed EBV expression in macrophages which had infiltrated primary lung lymphoma (16). EBV infects macrophages as well as B lymphocytes, $\mathrm{T}$ lymphocytes and epithelial cells. EBV-expressing macrophages may play important roles in cancer-causing chronic EBV infection and inflammation. To investigate the existence of EBV-expressing macrophages in several human cancers, we studied human cancer tissues that were already confirmed to express EBV oncogenes and the lytic infection protein BZLF1.

\section{Materials and methods}

Patients. Five nasopharyngeal carcinoma, 5 oral cancer, 10 thyroid carcinoma, 2 renal cell carcinoma (RCC), 2 testicular carcinoma, 11 uterine carcinoma, 4 cutaneous T-cell lymphoma, 2 anaplastic large-cell lymphoma cases and 1 case of chronic active EBV infection were examined. EBV expression was previously detected in the tumor cells. For a comparative study, 3 lichen planus, 2 Graves' disease, 2 thyroid nodular hyperplasia, 1 glomerulosclerosis case and 3 cases of normal uterine cervix were also examined. All samples used in this study have previously been described (4-16). None of the patients had a history or clinicopathological features indicative of an immunocompromised state.

Probes. BamHIW probes were transcribed from $2.27-\mathrm{kb}$ EBV BamHIW fragments from which the 'Alu-family'-like sequence had been deleted. The BamHIW fragment of EBV is a highly repetitive sequence that contains the mRNA leader sequence for EBNAs. The fragment was cloned into the pBluescript II SK ${ }^{+}$vector. cDNA of the BamHIY1Y2 (EBNA
LP) region was also cloned into pBluescript II SK ${ }^{+}$. The size of this cDNA was $153 \mathrm{bp}$. The sense and antisense probes were labelled with digoxigenin-11-UTP by in vitro transcription with T7 and T3 polymerases, respectively, using a commercial kit (Boehringer Mannheim, Mannheim, Germany). EBNA2 cDNA $(14,802-48,583$, including a spliced sequence) and EBER1 cDNA $(6,629-6,795)$ were synthesized through RT-PCR according to the method reported by Tierney et al (25) and cloned into the pGEM-T Easy Vector (Promega, Madison, WI, USA). The sizes of these cDNAs were 386 and $167 \mathrm{bp}$, respectively. The sense and antisense RNA probes were labelled with digoxigenin-11-UTP by in vitro transcription with T7 and SP6 polymerases, respectively, using a commercial kit (Boehringer Mannheim). The labelled BamHIW and EBNA2 riboprobes were then fragmented to $\sim 100$ bases in length by alkaline hydrolysis. The sense probe served as a negative control.

Messenger RNA in situ hybridization. Paraffin sections were prepared from formalin-fixed tissues from biopsied or surgically resected materials. Serial sections were cut to 3-5 $\mu \mathrm{m}$. After dewaxing and dehydration with graded ethanol, slides were treated with $0.2 \mathrm{~N} \mathrm{HCl}$ for $15 \mathrm{~min}$ at room temperature (RT) and rinsed with phosphate-buffered saline (PBS) for $5 \mathrm{~min}$ also at RT. They were then treated with $50 \mu \mathrm{g} / \mathrm{ml}$ proteinase $\mathrm{K}$ in PBS for $15 \mathrm{~min}$ at $37^{\circ} \mathrm{C}$ and immersed in $2 \mathrm{mg} / \mathrm{ml}$ glycine in PBS for $10 \mathrm{~min}$ at RT. Subsequently, the sections were refixed with $4 \%$ paraformaldehyde in PBS for $15 \mathrm{~min}$ and washed twice with PBS for $3 \mathrm{~min}$ at RT, then treated with $0.1 \mathrm{M}$ triethanolamine $(\mathrm{pH} 8.0)$ for $10 \mathrm{~min}$ at RT. After washing with PBS, the sections were dehydrated with ethanol and hybridized for $40 \mathrm{~h}$ at $37^{\circ} \mathrm{C}$ for EBNA2 and EBER1, $39^{\circ} \mathrm{C}$ for BamHIY1Y2 (EBNA LP) and $45^{\circ} \mathrm{C}$ for BamHIW in $4 \mathrm{X}$ SSC, $50 \%$ formamide, $1 \mathrm{X}$ Denhardt's solution, $5 \%$ dextran sulfate, $0.5 \mathrm{mg} / \mathrm{ml}$ salmon sperm DNA, $0.5 \mathrm{mg} / \mathrm{ml}$ yeast tRNA and $10 \mathrm{mM}$ dithiothreitol. After hybridization, the sections were washed twice with $2 \mathrm{X}$ SSC for $30 \mathrm{~min}$ and then twice with $0.5 \mathrm{X}$ SSC for $20 \mathrm{~min}$ with gentle shaking at RT. They were subsequently blocked with $1 \%$ skim milk (Difco) in $100 \mathrm{mM}$ Tris and $0.15 \mathrm{M} \mathrm{NaCl}$ (pH 7.5) for $30 \mathrm{~min}$ at RT. Next, they were reacted with 1:100 (for EBNA2) and 1:200 diluted (for BamHIW, BamHIY1Y2 and EBER1) alkaline phosphatase-labelled anti-DIG antibody (Boehringer Mannheim) in blocking buffer for $2 \mathrm{~h}$ at RT. After washing, the sections were incubated with nitroblue tetrazolium and X-phosphate (Boehringer Mannheim) in buffer containing $0.1 \mathrm{M}$ Tris, $0.1 \mathrm{M} \mathrm{NaCl}, 0.005 \mathrm{M} \mathrm{MgCl}_{2}$ and $1 \mathrm{mM}$ levamisole $(\mathrm{pH} 9.6)$ for $16 \mathrm{~h}$ at $\mathrm{RT}$. The reaction was stopped with EDTA, and then the slides were then dehydrated with graded ethanol and xylene and sealed with malinol. These methods are a modified version of those we previously reported (4-16).

Double staining with $m R N A$ in situ hybridization for EBV and immunostaining against macrophages. Tissue sections that had been prepared in the previous studies, after in situ hybridization, were immersed in $100 \%$ xylene, and the cover glasses were removed. After rehydration with a series of descending concentrations of ethyl alcohol and distilled water, the sections were exposed to microwaves $(500 \mathrm{~W})$ for $5 \mathrm{~min}$ in $10 \mathrm{mM}$ Tris and $1 \mathrm{mM}$ EDTA (pH 9.0) and digested with $0.05 \%$ trypsin in 
Table I. Summary of results.

\begin{tabular}{|c|c|c|c|c|c|c|}
\hline Disease & Histology & Case & Probe for ISH & Double-stained/CD68-positive ${ }^{a}$ & Rate & Average $^{b}$ \\
\hline \multirow[t]{5}{*}{ NPC } & $\mathrm{SCC}$ & 1 & BamHIW & $9 / 35$ & 0.26 & \\
\hline & SCC & 2 & BamHIW & $6 / 28$ & 0.21 & \\
\hline & SCC & 3 & BamHIW & $7.5 / 31.5$ & 0.24 & \\
\hline & SCC & 4 & BamHIW & $9 / 29$ & 0.31 & \\
\hline & $\mathrm{SCC}$ & 5 & BamHIW & $3 / 28$ & 0.11 & 0.226 \\
\hline \multirow[t]{6}{*}{ Oral cancer } & SCC & 1 & EBER1 & $27 / 59.5$ & 0.45 & \\
\hline & $\mathrm{SCC}$ & 2 & EBER1 & $12 / 30.6$ & 0.39 & \\
\hline & $\mathrm{SCC}$ & 3 & EBER1 & $4.5 / 14$ & 0.32 & \\
\hline & $\mathrm{SCC}$ & 3 & EBNA2 & $10 / 36$ & 0.28 & \\
\hline & $\mathrm{SCC}$ & 4 & EBNA2 & $11 / 41$ & 0.27 & \\
\hline & $\mathrm{SCC}$ & 5 & EBNA2 & $0 / 0$ & 0 & 0.285 \\
\hline \multirow[t]{3}{*}{ Lichen planus } & & 1 & EBER1 & $0 / 67$ & 0 & \\
\hline & & 2 & EBNA LP & $0 / 24$ & 0 & \\
\hline & & 3 & EBNA LP & $0 / 73$ & 0 & 0 \\
\hline \multirow[t]{11}{*}{ Thyroid ca. } & Pap. ca. & 1 & EBER1 & $5 / 20$ & 0.25 & \\
\hline & Pap. ca. & 2 & EBER1 & $3 / 20$ & 0.15 & \\
\hline & Pap. ca. & 3 & EBER1 & $7 / 34$ & 0.21 & \\
\hline & Pap. ca. & 3 & BamHIW & $2 / 18$ & 0.11 & \\
\hline & Pap. ca. & 4 & BamHIW & $1.5 / 14$ & 0.12 & 0.168 \\
\hline & SCC & 1 & EBER1 & $6 / 53$ & 0.11 & 0.11 \\
\hline & Undiff. ca. & 1 & EBER1 & $12.5 / 97.5$ & 0.13 & \\
\hline & Undiff. ca. & 2 & EBER1 & $12.7 / 43$ & 0.29 & \\
\hline & Undiff. ca. & 3 & EBER1 & $9.5 / 93$ & 0.10 & \\
\hline & Undiff. ca. & 4 & EBER1 & $10 / 36$ & 0.28 & \\
\hline & Undiff. ca. & 5 & EBER1 & $9 / 19.3$ & 0.47 & 0.248 \\
\hline \multirow[t]{2}{*}{ Graves' disease } & & 1 & BamHIW & $0 / 12$ & 0 & \\
\hline & & 2 & BamHIW & $0 / 13$ & 0 & \\
\hline \multirow[t]{2}{*}{ Nodular hyperplasia } & & 1 & EBER1 & $0 / 45$ & 0 & \\
\hline & & 2 & EBER1 & $0 / 51$ & 0 & 0 \\
\hline \multirow[t]{4}{*}{$\mathrm{RCC}$} & Clear cell & 1 & BamHIW & $1 / 9$ & 0.11 & \\
\hline & Clear cell & 1 & EBNA LP & $15 / 65$ & 0.23 & \\
\hline & Clear cell & 2 & BamHIW & $21 / 40$ & 0.47 & \\
\hline & Clear cell & 2 & EBNA LP & $30 / 70$ & 0.43 & 0.308 \\
\hline Glomerulosclerosis & & 1 & EBER1 & $0 / 4$ & 0 & 0 \\
\hline \multirow[t]{2}{*}{ Testicular ca. } & Seminoma & 1 & BamHIW & $2 / 12$ & 0.17 & \\
\hline & Seminoma & 2 & BamHIW & $8 / 43$ & 0.19 & 0.185 \\
\hline \multirow[t]{6}{*}{ Uterine CIN3 } & $\mathrm{SCC}$ & 1 & EBER1 & $1 / 3.7$ & 0.27 & \\
\hline & SCC & 1 & EBNA2 & $1 / 1.7$ & 0.59 & \\
\hline & $\mathrm{SCC}$ & 2 & EBER1 & $5.5 / 10.75$ & 0.51 & \\
\hline & $\mathrm{SCC}$ & 2 & EBNA2 & $3.7 / 15.7$ & 0.24 & \\
\hline & $\mathrm{SCC}$ & 3 & EBER1 & $11 / 33.4$ & 0.32 & \\
\hline & $\mathrm{SCC}$ & 3 & EBNA2 & $9.5 / 67.5$ & 0.14 & 0.387 \\
\hline \multirow[t]{7}{*}{ Invasive uterine cervical ca. } & $\mathrm{SCC}$ & 1 & EBNA2 & $39 / 52$ & 0.75 & \\
\hline & $\mathrm{SCC}$ & 2 & EBNA2 & $12 / 37$ & 0.32 & \\
\hline & $\mathrm{SCC}$ & 3 & EBNA2 & $20.5 / 40.5$ & 0.51 & \\
\hline & $\mathrm{SCC}$ & 4 & EBNA2 & $4 / 17$ & 0.24 & \\
\hline & $\mathrm{SCC}$ & 5 & BamHIW & $26 / 46.5$ & 0.56 & \\
\hline & SCC & 6 & EBER1 & $23.7 / 78.7$ & 0.30 & \\
\hline & $\mathrm{SCC}$ & 6 & EBNA2 & $20.4 / 60.6$ & 0.34 & 0.432 \\
\hline
\end{tabular}


Table I. Continued.

\begin{tabular}{|c|c|c|c|c|c|c|}
\hline Disease & Histology & Case & Probe for ISH & Double-stained/CD68-positive ${ }^{a}$ & Rate & Average $^{b}$ \\
\hline \multirow[t]{5}{*}{ Normal cervix } & & 1 & EBER1 & $0 / 0$ & 0 & \\
\hline & & 2 & EBER1 & $0 / 3$ & 0 & \\
\hline & & 2 & EBNA2 & $0 / 7.5$ & 0 & \\
\hline & & 3 & EBER1 & $0 / 13.5$ & 0 & \\
\hline & & 3 & EBNA2 & $0 / 7$ & 0 & 0 \\
\hline \multirow[t]{2}{*}{ Uterine cp. ca. } & Adenoca. & 1 & EBNA2 & $26.5 / 64$ & 0.41 & \\
\hline & Adenoca. & 2 & EBER1 & $0 / 0$ & 0 & 0.205 \\
\hline \multirow[t]{4}{*}{ CTCL } & & 1 & EBER1 & $4.5 / 33$ & 0.13 & \\
\hline & & 2 & EBER1 & $8.6 / 22$ & 0.39 & \\
\hline & & 3 & EBNA2 & $10 / 37$ & 0.27 & \\
\hline & & 4 & EBNA2 & $12.5 / 34$ & 0.37 & 0.29 \\
\hline \multirow[t]{2}{*}{ ALCL } & & 1 & BamHIW & $6 / 40$ & 0.15 & \\
\hline & & 2 & BamHIW & $4 / 39$ & 0.10 & 0.125 \\
\hline Chr. ac. EBV infect. & & 1 & EBNA LP & $2 / 2$ & 1 & \\
\hline
\end{tabular}

${ }^{a}$ Average of 3-5 photographs at $\times 400$ magnification. ${ }^{b}$ Average rate of the disease. ISH, in situ hybridization; NPC, nasopharyngeal carcinoma; SCC, squamous cell carcinoma; BamHIW, BamHIW fragment of EBV DNA; EBER1, EBV-encoded small non-polyadenylated RNA-1; EBNA2, EBV nuclear antigen-2; EBNA LP, EBV nuclear antigen-leader protein; Thyroid ca., thyroid carcinoma; Pap. ca., papillary carcinoma; Undiff. ca., undifferentiated carcinoma; RCC, renal cell carcinoma; Clear cell, clear cell carcinoma; Testicular ca., testicular carcinoma; CIN3, cervical intraepithelial neoplasia 3; ca., carcinoma; cp. ca., corpus carcinoma; Adenoca., adenocarcinoma; CTCL, cutaneous T-cell lymphoma; ALCL, anaplastic large-cell lymphoma; Chr. ac. EBV infect., chronic active EBV infection.

PBS at $37^{\circ} \mathrm{C}$ for $60 \mathrm{~min}$. They were subsequently immersed in $3 \% \mathrm{H}_{2} \mathrm{O}_{2}$ in methanol, washed with PBS and treated with x25 diluted anti-CD68 mouse monoclonal antibody (Dako, Glostrup, Denmark) for $60 \mathrm{~min}$ at RT. Finally, the tissue sections were treated with a staining kit (Histofine Simple Stain NAX-PO(M); Nichirei BioScience, Tokyo, Japan) for $30 \mathrm{~min}$.

\section{Results}

To clarify the presence of EBV expression in TAMs, we carried out immunohistochemical staining using the antiCD68 monoclonal antibody in sections already hybridized with EBV mRNA by in situ hybridization. Tissue specimens of 5 nasopharyngeal carcinoma, 5 oral cancer, 10 thyroid carcinoma (involving 4 cases of papillary carcinoma, 1 of squamous cell carcinoma and 5 of undifferentiated carcinoma), 2 renal cell carcinoma, 2 testicular carcinoma, 3 uterine cervical intraepithelial neoplasia, 8 invasive uterine carcinoma (involving 6 cases of cervical squamous cell carcinoma and 2 of corpus adenocarcinoma), 4 cutaneous T-cell lymphoma, 2 anaplastic large-cell lymphoma cases and 1 case of chronic active EBV infection were prepared. For a comparative study, oral mucosal tissues of 3 cases of lichen planus, thyroid tissues of 2 cases (each of Graves' disease and nodular hyperplasia), kidney tissue of 1 case of glomerulosclerosis and mucosal tissue of 3 cases of normal cervix were also prepared. Hybridization signals appeared blue-purple in the nucleus with the EBER1 probe and in the cytoplasm with the others (BamHIW, EBNA2 and
EBNA LP), whereas immunohistochemical staining with CD68 appeared dark brown in the cytoplasm. The results of double staining with EBV mRNA in situ hybridization and CD68 immunostaining are summarized in Table I and representative images are shown in Fig. 1. Doublestained TAMs were detected in almost all tissues of the EBV-associated neoplasms examined. Generally, the more macrophages were detected in the tissue, the more they were double-stained. Although the number of TAMs was variable between cases, the ratio of double-stained macrophages to all macrophages was highest in the uterine cervical carcinoma, then oral cancer, undifferentiated thyroid carcinoma and nasopharyngeal carcinoma, when restricted to diseases for which we examined more than 5 cases (Table I). In most cases, macrophages also infiltrated into each comparative non-cancerous tissue, whereas they were not double-stained (Table I, Fig. 1c). In the nasopharyngeal carcinoma of case 1, tissue around the cancer showed many EBV-expressing epithelial cells (small arrowhead), a moderate number of infiltrating macrophages (large arrowhead) and several double-stained macrophages (double arrowhead). Since both signals of BamHIW and CD68 staining were expressed in the cytoplasm, the color of double-stained cells appeared black (Fig. 1a). In the oral cancer case 1, EBER1 signals were expressed in the nucleus and CD68 in the cytoplasm (Fig. 1b). In the case of lichen planus, a non-cancerous oral disease, there were many macrophages stained with CD68; however, no double-stained macrophage was observed (Fig. 1c). In the thyroid carcinomas, undifferentiated carcinoma expressed more EBV RNA than the papillary carcinoma cases (6); 


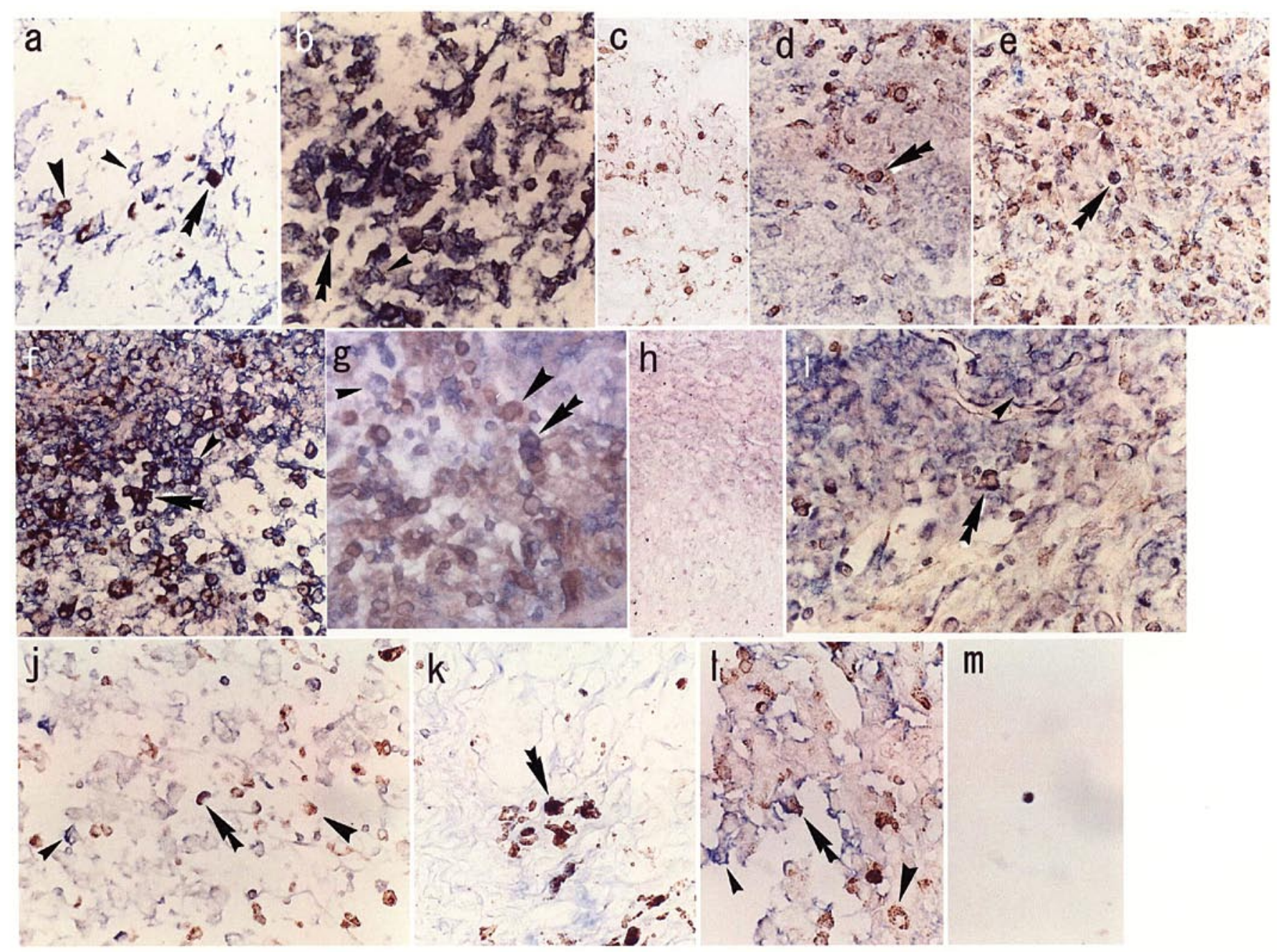

Figure 1. Results of the double staining of EBV mRNA on in situ hybridization and immunostaining with CD68. EBV-expressing cells are indicated by the small arrowhead; macrophages are indicated by the large arrowhead; double-stained macrophages are indicated by the double arrowhead. (a) Nasopharyngeal carcinoma, case 1, BamHIW antisense probe, x40; (b) oral cancer, case 1, EBER1 antisense probe, x40; (c) lichen planus for non-cancerous control of oral cancer, case 1, EBER1 antisense probe, x20; (d) thyroid papillary carcinoma, case 3, EBER1 antisense probe, x40; (e) thyroid undifferentiated carcinoma, case 1, EBER1 antisense probe, x40; (f) uterine cervical carcinoma, case 1, EBNA2 antisense probe, x40; (g) uterine corpus carcinoma, case 1, EBNA2 antisense probe, $x 40$; (h) normal cervix, case 1, EBER1 antisense probe, $x 20$; (i) renal cell carcinoma, case 2, BamHIW antisense probe, x40; (j) testicular carcinoma, case 2, BamHIW antisense probe, x40; (k) cutaneous T-cell lymphoma, case 4, EBNA2 antisense probe, x40; (1) anaplastic large-cell lymphoma, case 1, EBNA2 antisense probe, $\mathrm{x} 40$; (m) chronic active EBV infection, case 1, EBNA LP antisense probe, $\mathrm{x} 40$.

however, the number of double-stained macrophages was not significantly higher in the undifferentiated than in the papillary carcinomas (Table I). The number of TAMs that had infiltrated the uterine tissue was higher in the uterine cervical than in the uterine corpus carcinoma cases, and double staining was clearer in the former than in the latter (Fig. If and g). EBV expression of CIN was similar to invasive cervical carcinoma (9), and the number of doublestained macrophages was not significantly different between CIN and invasive carcinoma (Table I). The normal cervix showed few macrophages in the tissue (Fig. 1h). TAMs dually expressing EBV and CD68 were observed in the renal cell (Fig. 1i) and testicular (Fig. 1j) carcinomas. Moreover, in the tissues of the cutaneous T-cell lymphoma and anaplastic large-cell lymphoma, dually expressed TAMs were detected (Fig. 1k and 1). Bone marrow macrophages derived from chronic active EBV infection also showed double staining for EBV and CD68 (Fig. 1m).

\section{Discussion}

In the present study, double-stained TAMs were detected in almost all tissues of the EBV-associated neoplasms examined. Tissues from normal controls or those from non-cancerous disease cases sometimes contained many macrophages; however, they were not TAMs and were never double-stained. On the other hand, macrophages in a case with chronic active EBV infection (without any neoplasms) were also doublestained (Fig. 1m). We previously reported EBV expression in cultured macrophages from normal tissues of the bronchus and testis, and in cultured epididymitis macrophages (22). In the present study, however, macrophages in the normal or non-cancerous tissues did not show EBV expression. This may have been due to the selection of EBV-carrying macrophages, which is very rare in normal or non-cancerous tissues, but has a growth advantage in the process of cell culture. We previously reported EBV-expressing macrophages in the 
parotid tumor, non-Hodgkin's lymphoma (22), LCH $(23,24)$ and primary lung lymphoma (16). These results indicate that TAMs of EBV-related neoplasms as well as macrophages infiltrating tissues with chronic active EBV infection express EBV mRNA. In the case of chronic active EBV infection, the selection of EBV-carrying macrophages, which is similar to cell culture, may occur in the bone marrow.

Furthermore, double-stained TAMs were detected in the thyroid papillary carcinoma and CIN at almost the same level as in the thyroid undifferentiated and invasive cervical carcinomas, respectively. This suggests the earlier association of TAMs in the process of EBV oncogenesis.

As mentioned previously, most of these tumors were already confirmed to express EBV oncogene EBNA2 and lytic infection protein BZLF1; therefore, it can be said that TAMs in EBV-related tumors involve EBV-carrying macrophages, and may also produce EBV. We reported that childhood LCH expressed high levels of EBV lytic infection protein, and that in one case the administration of acyclovir resulted in complete remission (23). If inflammation caused by EBV production in the tumor tissue is always as intense as we observed, we can expect that the administration of an anti-herpesvirus drug will be more effective and safer than the usual anti-cancer chemotherapy. These lytic infections of TAMs may also be a target of inflammation. We observed that the more macrophages were detected in the tissue, the more they were double-stained by insitu hybridization and CD68 immunostaining. This suggests a strong correlation between EBV-carrying TAMs and inflammation. Notably, a correlation between infiltrating macrophages and the risk or poor prognosis of cervical intraepithelial neoplasia (26), uterine endometrioid adenocarcinoma (27) and RCC (28) was reported, although it is unknown whether EBV infection is associated with these macrophages.

Chemical agent-associated chronic inflammation with oxidative and nitrative DNA damage was reported by Kawanishi et al. They described 8-nitroguanine as a potential biomarker for evaluating the risk of inflammation-related carcinogenesis (29). The correlation between 8-nitroguanine and EBV has been studied in cases of nasopharyngeal carcinoma (30) and oral cancer (31). Moreover, Ma et al showed that the cells responsible for the reaction are macrophages (30).

Recently, the suppression of HIV replication by human herpesvirus 6 (32) or 7 (33) was reported. Furthermore, it was reported that latently infected murine- $\gamma$ herpesvirus 68 , which is genetically very similar to EBV, confers resistance against Listeria monocytogenes and Yersinia pestis in mice (34). Such virus-virus or virus-microbe interactions may be important when considering oncogenesis due to inflammation caused by viral infection. We previously reported that EBV genes of BamHIW (9), EBNA2 (10) and EBNA LP (11) were expressed in uterine cervical carcinoma tissue. The frequency of the correlation was higher with EBV than with human papillomavirus (HPV) (9). Almost all cervical carcinoma samples also carried the HPV16 gene (9), and E6-E7 proteins of HPV16 were reported to induce uncontrollable cell growth (35). Through this study, TAMs in CIN as well as cervical and a part of corpus carcinoma were shown to express EBV mRNA. Therefore, we hypothesize that EBV infection may synergistically act with HPV to cause the development or progression of cancer through the long-term inflammation induced by infiltrating macrophages carrying EBV. EBV-associated tumors other than uterine carcinoma were also suspected to be caused by long-term inflammation with EBV alone or EBV and another unidentified virus or microbe. Moreover, the role of macrophages, not only in inflammation but also in the interaction between viruses or viruses and microbes, should be clarified. Through these studies of tumor and virus-related inflammation involving macrophages, it may be possible to fully elucidate the dynamic mechanism of EBV oncogenesis.

\section{Acknowledgements}

We thank Drs T. Sasagawa (Kanazawa University), K. Kawahara (Osaka Prefectural Medical Center for Respiratory and Allergic Diseases), T. Shinka, S. Tamura, H. Nakamine (Wakayama Medical College), K. Horii (Osaka Dental University), S. Yanoma (Yokohama City University), T. Kozuka and T. Oka (Osaka National Hospital) for their generous gifts of materials. This study was supported by a Grant-in-Aid for Cancer Research from the Ministry of Health, Labour and Welfare of Japan.

\section{References}

1. Balkwill $\mathrm{F}$ and Mantovani $\mathrm{A}$ : Inflammation and cancer: back to Virchow? Lancet 357: 539-545, 2001.

2. Coussens LM and Werb Z: Inflammation and cancer. Nature 420: 860-867, 2002.

3. IARC World Cancer Report. Chronic Inflammations. IARC Press, Lyon, pp56-61. 2003.

4. Shimakage M, Horii K, Tempaku A, Kakudo K, Shirasaka T and Sasagawa T: Association of Epstein-Barr virus with oral cancers. Hum Pathol 33: 608-614, 2002.

5. Shimakage M, Sasagawa T, Yoshino K, Yutsudo M, Kimura M, Yamamoto N and Yanoma S: Expression of Epstein-Barr virus in mesopharyngeal and hypopharyngeal carcinomas. Hum Pathol 30: 1071-1076, 1999.

6. Shimakage M, Kawahara K, Sasagawa T, Inoue H, Yutsudo M, Yoshida A and Yanoma S: Expression of Epstein-Barr virus in thyroid carcinoma correlates with tumor progression. Hum Pathol 34: 1170-1177, 2003.

7. Shimakage M, Kawahara K, Harada S, Sasagawa T, Shinka T and Oka T: Expression of Epstein-Barr virus in renal cell carcinoma. Oncol Rep 18: 41-46, 2007.

8. Shimakage M, Oka T, Shinka T, Kurata A, Sasagawa T and Yutsudo M: Involvement of Epstein-Barr virus expression in testicular tumors. J Urol 156: 253-257, 1996.

9. Sasagawa T, Shimakage M, Nakamura M, Sakaike J, Ishikawa H and Inoue M: Epstein-Barr virus (EBV) genes expression in cervical intraepithelial neoplasm and invasive cervical cancer: a comparative study with human papillomavirus (HPV) infection. Hum Pathol 31: 318-326, 2000.

10. Shimakage M and Sasagawa T: Detection of Epstein-Barr virusdetermined nuclear antigen-2 mRNA by in situ hybridization. $\mathrm{J}$ Virol Methods 93: 23-32, 2001.

11. Shimakage M, Harada S, Kawahara K, Oka T, Yanoma S, Horii K and Sasagawa T: Detection of Epstein-Barr virus nuclear antigen leader protein expression in various human cancers. In: New Developments in Epstein-Barr Virus Research. Umar CS (ed). Nova Science Publishers, New York, pp261-276, 2006.

12. Shimakage M, Dezawa T, Tamura S, Tabata T, Aoyagi N, Koike M, Inoue H, Yutsudo M, Hakura A and Ikegami N: A Ki-1-positive cell line expressing Epstein-Barr virus antigen established from a child with Ki-positive lymphoma. Intervirology 36: 215-224, 1993.

13. Shimakage M, Nakamine H, Tamura S, Takenaka T, Yutsudo M and Hakura A: Detection of Epstein-Barr virus transcripts in anaplastic large-cell lymphomas by mRNA in situ hybridization. Hum Pathol 28: 1415-1419, 1997. 
14. Shimakage M, Sasagawa T, Kawahara K, Yutsudo M, Kusuoka H and Kozuka T: Expression of Epstein-Barr virus in cutaneous T-cell lymphoma including mycosis fungoides. Int J Cancer 92: 226-231, 2001

15. Nakajima H, Shimakage M, Takeda Y, Furutama D, Sugino M, Kimura F, Shibayama Y and Hanafusa T: Epstein-Barr virusassociated primary leptomeningeal lymphoma. Eur J Neurol 13: e4-e6, 2006

16. Shimakage M, Sakamoto H, Harada S, Sasagawa $T$ and Kodama K: Expression of the Epstein-Barr virus in lymphoproliferative diseases of the lung. Oncol Rep 17: 1347-1352, 2007.

17. Hoshikawa Y, Satoh Y, Murakami M, Maeta M, Kaibara N, Ito $\mathrm{H}$, Kurata $\mathrm{T}$ and Sairenji T: Evidence of lytic infection of Epstein-Barr virus (EBV) in EBV-positive gastric carinoma. J Med Virol 99: 351-359, 2002

18. Takasaka N, Tajima M, Okinaga K, Satoh Y, Hoshikawa Y, Katsumoto T, Kurata T and Sairenji T: Productive infection of Epstein-Barr virus (EBV) in EBV-genome-positive epithelial cell lines (GT38 and GT39) derived from gastric tissues. Virology 247: 152-159, 1998.

19. Lewis CE and Pollard JW: Distinct role of macrophages in different tumor microenvironments. Cancer Res 66: 605-612, 2006.

20. Revoltella RP, Vigneti E, Fruscalzo A, Park M, Ragona G, Rocchi G and Calef E: Epstein-Barr virus DNA sequences in precursor monocyte-macrophage cell line established from the bone marrow of children with maturation defects of haematopoiesis. J Gen Virol 70: 1203-1215, 1989.

21. Savard M, Belanger C, Tardif M, Gourde P, Flamand L and Gosselin J: Infection of primary human monocytes by EpsteinBarr virus. J Virol 74: 2612-2619, 2000.

22. Shimakage M, Kimura M, Yanoma S, Ibe M, Yokota S, Tsujino G Kozuka T, Dezawa T, Tamura S, Ohshima A, Yutsudo M and Hakura A: Expression of latent and replicative-infection genes of Epstein-Barr virus in macrophage. Arch Virol 144: 157-166, 1999.

23. Shimakage M, Sasagawa T, Kimura M, Shimakage T, Seto S, Kodama K and Sakamoto H: Expression of Epstein-Barr virus in Langerhans' cell histiocytosis. Hum Pathol 35: 862-868, 2004.

24. Shimakage M: Langerhans cell histiocytosis and its relationship with Epstein-Barr virus - reply. Hum Pathol 37: 1509-1511, 2006.

25. Tierney RJ, Steven N, Young LS and Rickinson AB: EpsteinBarr virus latency in blood mononuclear cells, analysis of viral gene transcription during primary infection and in the carrier state. J Virol 68: 7374-7385, 1994
26. Hammes LS, Tekmal RR, Naud P, Edelweiss MI, Kirma N, Valente PT, Syrjanen KJ and Cunha-Filho JS: Macrophages, inflammation and risk of cervical intraepithelial neoplasia (CIN) progression - clinicopathological correlation. Gynecol Oncol 105: 157-165, 2007.

27. Soeda S, Nakamura N, Ozeki T, Nishiyama $H$, Hojo $H$, Yamada H, Abe M and Sato A: Tumor-associated macrophages correlate with vascular space invasion and myometrial invasion in endometrial carcinoma. Gynecol Oncol 109: 122-128, 2008.

28. Hamada I, Kato M, Yamasaki T, Iwabuchi $K$, Watanabe $T$, Yamada T, Isoyama S, Ito $\mathrm{H}$ and Okada $\mathrm{K}$ : Clinical effects of tumor-associated macrophages and dendritic cells on renal cell carcinoma. Anticancer Res 22: 4281-4284, 2002.

29. Kawanishi S, Hiraku Y, Pinlaor S and Ma N: Oxidative and nitrative DNA damage in animals and patients with inflammatory diseases in relation to inflammation-related carcinogenesis. Biol Chem 387: 365-372, 2006.

30. Ma N, Kawanishi M, Hiraku Y, Murata M, Huang GW, Huang Y, Luo DZ, Mo WG, Fukui Y and Kawanishi S: Reactive nitrogen species-dependent DNA damage in EBV-associated nasopharyngeal carcinoma: the relation to STAT3 activation and EGFR expression. Int J Cancer 122: 2517-2525, 2008.

31. Chayarit P, Ma N, Hiraku Y, Pinlaor S, Yangvanit P, Jintakanon D, Murata M, Oikawa S and Kawanishi S: Nitrative and oxidative DNA damage in oral lichen planus in relation to human oral carcinogenesis. Cancer Sci 96: 553-559, 2006.

32. Grivel J-C, Ito Y, Faga G, Santoro F, Shaheen F, Malnati MS, Fitzgerald W, Lusso P and Margolis L: Suppression of CCR5but not CXCR4-tropic HIV-1 in lymphoid tissue by human herpesvirus 6. Nat Med 7: 1232-1235, 2001

33. Lisco A, Grivel JC, Biancotto A, Vanopouille C, Origgi F, Malnati MS, Schols D, Lusso P and Margolis LB: Viral interaction in human lymphoid tissue: human herpesvirus 7 suppresses the replication of CCR5-tropic human immunodeficiency virus type 1 via CD4 modulation. J Virol 81: 708-717, 2007.

34. Barton ES, White DW, Cathelyn JS, Brett-McClellan KA, Engle M, Diamond D, Miller VL and Virgin HW IV: Herpesvirus latency confers symbiotic protection from bacterial infection. Nature 447: 326-330, 2007.

35. Sasagawa T: Human papillomavirus infection and cervical cancer. Biomed Rev 14: 75-93, 2003. 